\title{
40
}

\section{Model and simulation based flexible production management system}

\author{
Prof. Dr.-Ing. W. Maßberg \\ Michael Bäcker \\ Harald Schallner \\ Ingo Thiem \\ Lehrstuhl für Produktionssysteme und Prozeßleitttechnik \\ Universitätsstraße 150 \\ Gebäude IB 2/28 \\ D-44780 Bochum \\ Telephone: 0234/700-6310 \\ Telefax: 0234/7094-157 \\ E-Mail: massberg@lps.ruhr-uni-bochum.de
}

\begin{abstract}
The objective of the project MOBILEIT-S is to develop a model based toolbox that offers the possibility of designing and configuring integrated manufacturing control systems with simulation kernel. The basis of this production management system is a metamodel that provides the structural framework for general reference models of the manufacturing order processing for different organizations such as single item or serial productions. The metamodel of the manufacturing control is derived from the general organizational 'Viable System Model' and describes the minimum requirements of an information system from the perspective of information, communication and control. It is a cybernetic model that is based on the ideas of Second Order Cybernetics which makes it possible to design the necessary communication and control structures for an organization from a sociotechnical perspective.
\end{abstract}




\section{Keywords}

Model, Second Order Cybernetics, manufacturing control, Viable System Model, simulation

\section{INTRODUCTION}

In order to compete successfully in the global market companies have to control all factors such as costs innovation, quality and time. For this reason tasks in companies are being allocated in a new way and increasingly solved by team work. Many companies have started with extensive reorganization processes. In this context, decentralization is an important objective of the organizational design. The reorganization process is characterized by the following principles (Figure 1) (Hiersch, 1996):

\section{Employee orientation:}

Since the phase of Taylorism, the focus of attention has shifted to the individual with his intelligence, creativity and talent to improvise has moved again in the center of interest. The entrepreneurial goal is to use these capabilities to open new potentials of rationalization. The capabilities of the employee can best be developed and used in the scope of decentralized organizational structures.

The ability to co-operate with internal and external partners:

The success of the company depends not only on their products and services but increasingly on the processes used to produce them. Therefore, the focus has to be on the optimization of entrepreneurial business processes with respect to the satisfaction of internal and external customers (Grabowski, 1995). The objective is to increase customer satisfaction. Thus, the processes in a company have to be oriented towards the customer and continuously adjusted to his demands. 


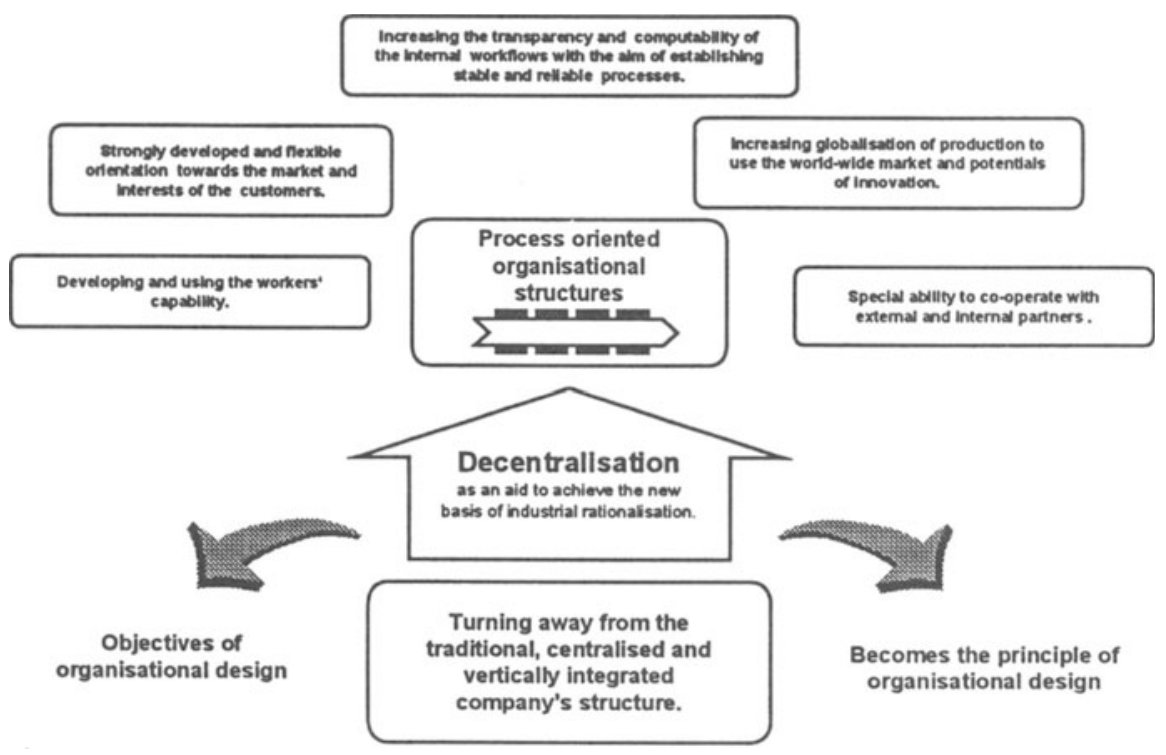

Figure 1 Principles of organizational rationalization

Strongly developed and flexible orientation towards the market:

The ability to co-operate is inseparably connected with the orientation toward the market. For this reason it is necessary to reorganize in a process-oriented way the operational sequences in a company according to the requests and demands of the customer (Wiegershaus, 1996). The organizational design must optimize the activities of a process. This process orientation is the prerequisite for a customer orientation. Moreover, this approach can lead to a considerable improvement of the processes (Eversheim, 1995). An orientation of the entrepreneurial activities towards the value-creating process provides greater transparency of the internal operational sequences.

In manufacturing, such a process-oriented organization is realized by hybrid manufacturing structures. In these structures partly autonomous, decentralizedscheduled manufacturing units work together with centralized-scheduled units within internal customer-supplier-relations in the manufacturing order processing. This future-oriented factory structure is based on the principle of modularity, the building of network structures as well as the implementation of team- and groupwork (Wildemann, 1996).

\section{SITUATION OF MANUFACTURING CONTROL SYSTEMS}

Appropriate aids are required to support the employees in their new work environment and in the realization of their new additional responsibilities. Control and information systems are therefore needed, that are oriented towards the total process and adjusted to continuously changing operational sequences (Poensgen, 1994). PPC and manufacturing control systems that are currently available do not 
keep up with the flexibility of business processes. Current PPC- and manufacturing control systems do not have appropriate structures and operational sequences that fulfill the requirements of the new forms of organizations (Table l).

The causes for the critics are, on the one hand, the inflexible and old soft- and hardware structures (DLR, 94) and on the other hand, the out-dated models of manufacturing control which are only of limited use but upon which the present systems are based (Linsen, 1995) (Herrmann, 1995). Often they are too inflexible and cannot be adapted to the current requirements of new organizational structures because they are oriented by old organizational models (Linsen, 1995). The functional technical design of the PPC- and manufacturing control systems corresponds to the organizational structures that are based on the division of labor and the division orientation (Poensgen, 1995). For the user the often oversized systems have a confusing offer of functions (VDW, 1995) (Herrmann, 1995). Often the weak points of a functional enterprise are reflected in particular by the software used (Poensgen, 1995).

Table 1 Future oriented change in manufacturing control

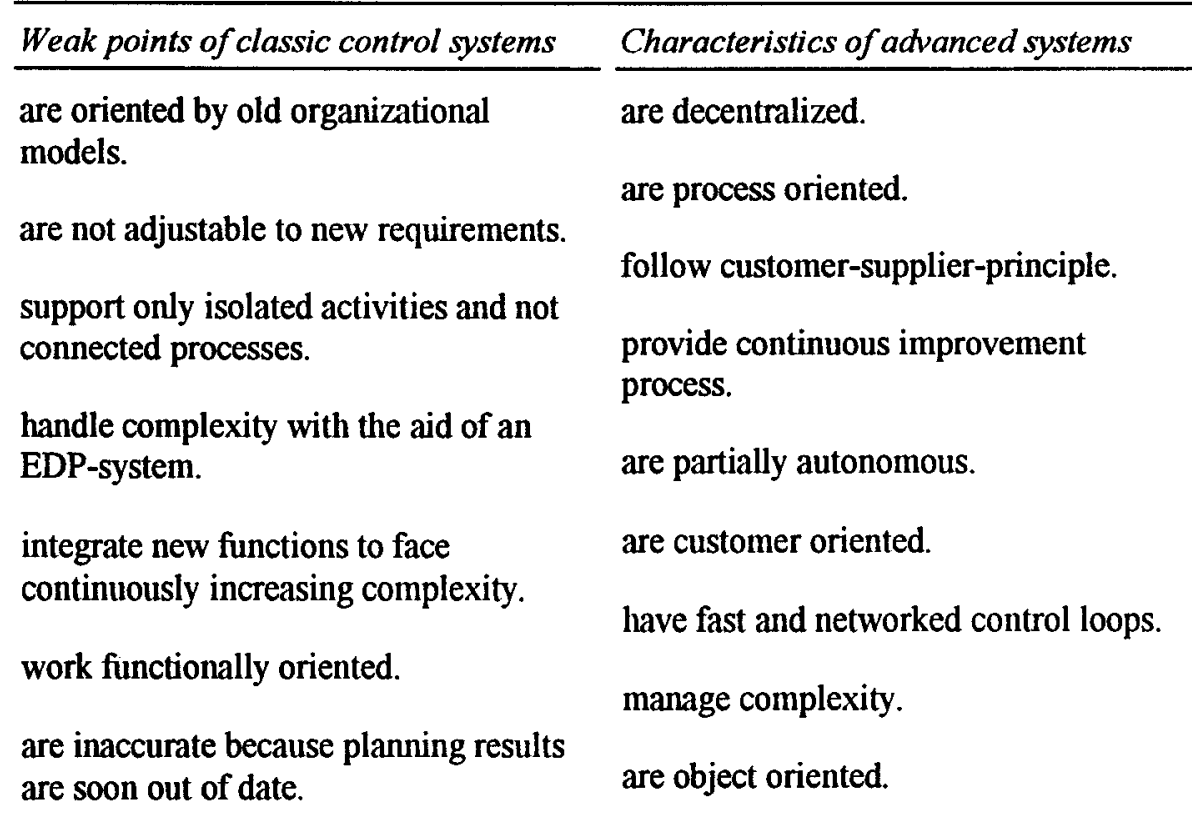

In conclusion, it can be said that the available PPC- as well the manufacturing control systems do not meet the requirements of decentralized organizational structures. However, control and planing tools should decisively support decentralization (VDW, 1995). Information systems have to fit into the chosen organizational structures and processes without changing the general conditions. It is not the operational sequence in manufacturing that should be adjusted to the 
information system but the other way round. For this reason there is need for ITsystems for the manufacturing control that correspond to decentralize manufacturing structures.

IT-systems for manufacturing control no longer need to be designed from a purely technical perspective. Similar to the design of working systems it is required that the design of information systems has to be oriented to the needs of the individual. The role of the manufacturing control systems has changed. It should not make decisions for the employee but support him at his work. In this context the employee has an important position as the final decision-maker. So far the shop floor control has been perceived as a technical system in general. The role of the employee and the resulting consequences for the design of the manufacturing control and the supporting information systems have been neglected. The essential objective of previous approaches for shop floor control was to describe the complex processes using mathematical models which should lead to a more exact planning. By the developing of these planning methods far away from the shop floor (Herrmann, 1995) the sociotechnical approach was mainly ignored.

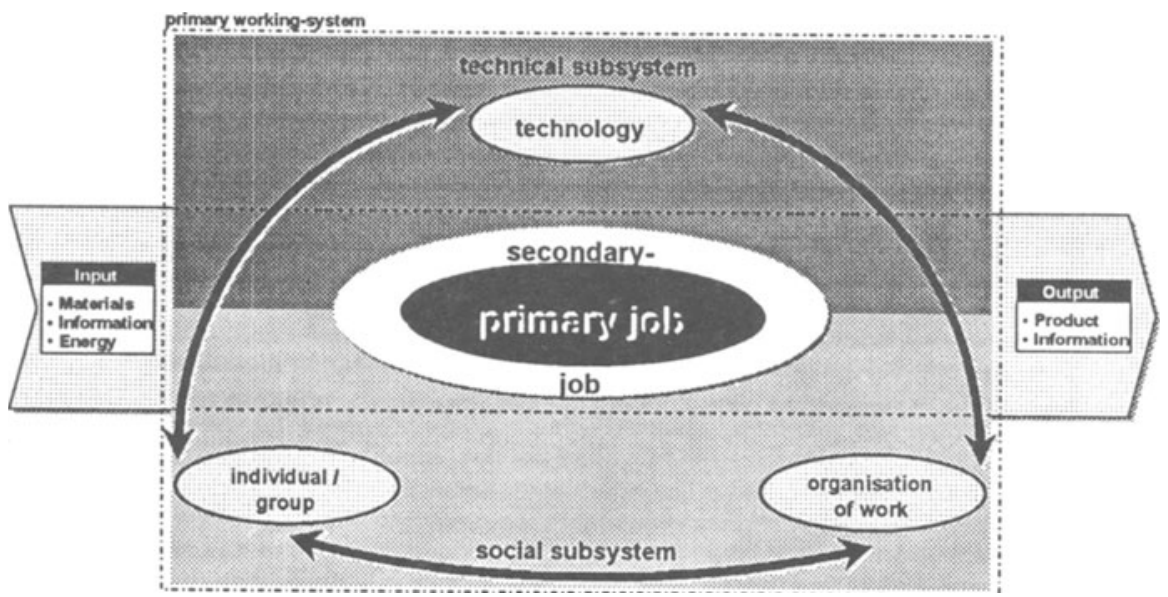

Figure 2 The social technical system

Therefore new information systems should be designed which consider the triangle relationship that is used in the sociotechnical system design (Figure 2): individual, technology and organization.

The concept of the sociotechnical system approach proceeds on the assumption that a working system consists of a technical and social subsystem. The technical subsystem comprises the technological and spatial conditions of the working system (Ulrich, 1994). The social subsystem consists of the organizational members with their individual and group related needs.

A working system is build to fulfill a primary job which transforms material, information and energy to a product or information of value. The secondary job of a working system is to maintain itself and to control the primary job.

The sociotechnical system approach forms an essential theoretical basis of the modern psychology of labor. According to it primary working systems are 
considered as goal oriented, open and dynamic systems that are in contact with their environment by the exchange of in- and outputs.

The sociotechnical concept demands an holistic approach to the solution of a problem. It accepts the complexity resulting from the interaction of human being and technique (Sydow, 1985).

An information system for the manufacturing control has to consider the needs of the group members, the organizational restrictions as well as the effect of technical systems. Likewise, it has to enable the complexity of an organization, resulting from the different factors of influence, to operate.

Bearing in mind these designing fields and the criticisms mentioned the following aspects have to be considered when previously designing information systems (Figure 3):

\section{Organization as a design aspect for a control system}

The organization of a system means its planned design. It represents a basis for the connections and interactions between the workers, the used technique and the information that is necessary to process the task. For this purpose the organization states rules that determine these relationships (Probst, 1993). The objective of such an organized working system is to fulfill the purpose of the system.

Consequently, the manufacturing organization represents the basis of the relationship between the employees that participate in the manufacturing process, the machines and the necessary information. Organization and technology have to be co-ordinated according to the overall purpose of the system. They have to provide a common basis for self-organization, self-control and autonomy. Only in this way is it possible to use the potential of the employee in order to continuously optimize the working system and to reach set targets.

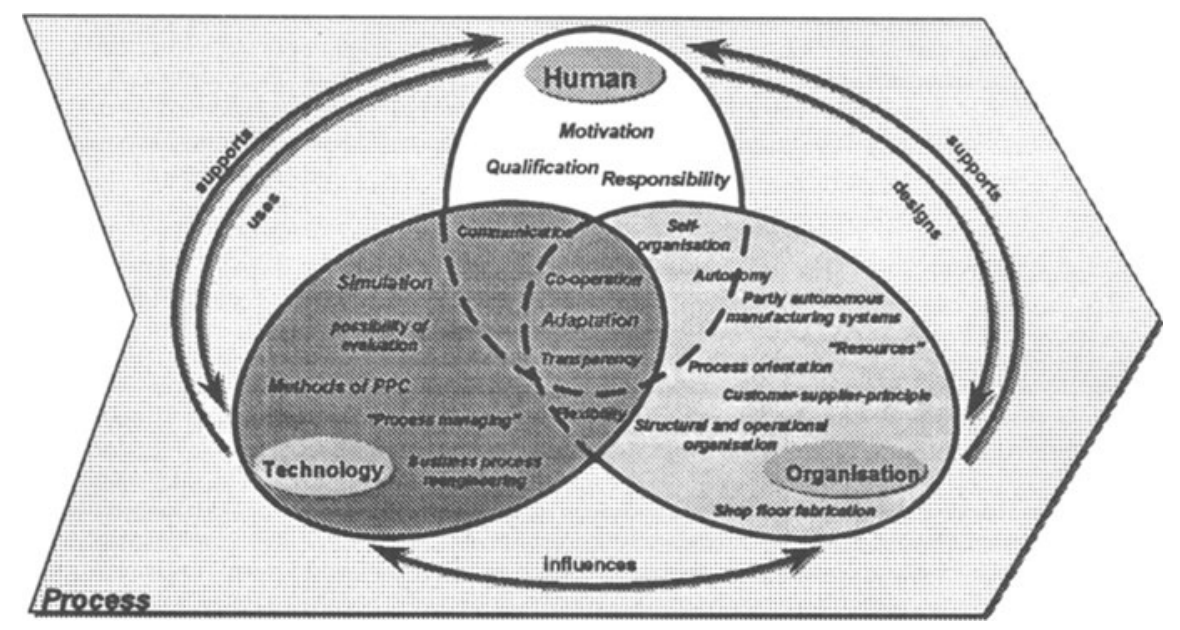

Figure 3 Interaction between human, technology and organizational factors 
For this reason the information, planning and control functions must be by and large shifted into the individual working area (Schwaninger, 1994). The information systems for the support of decentralized manufacturing structures have to be adapted to the organizational structures. Consequently, demands on the design of the manufacturing control must be analyzed with respect to autonomy and self-organization. In this way, the information processes can be closely approximated to the real processes.

\section{The individual as designing aspect for control systems}

The individual is the focus of labor oriented designing concepts. In order to use his potential for the optimization of the working system it is necessary to design systems and their tasks according to work and human oriented characteristics. The working task is the core of the sociotechnical view. It is the intersection between organization and individual (Volpert, 1987). The task has to meet different requirements to induce motivation which leads to the optimal realization of the task. The worker has to posses the skills needed for the working processes and the necessary aids. (Ulrich, 1994). The structural features of any task must be designed in a way to activate the worker to either continue or to finish their work In other words they should motivate the acting person to fulfill his task.

The following characteristics of a task design produce motivation: holistic work, variety of demands, possibilities of social interaction, autonomy, as well as possibilities for learning and development.

When designing a manufacturing system which fulfills the requirements of a human oriented design, it is therefore necessary to check which influences these characteristics have on the design of the manufacturing control and which consequences this again has on the design of an information system. In particular, information flows must be checked and communication structures have to be designed to support the self-organization and co-operation with other manufacturing sections.

\section{Technology as design aspect for a control system}

Here, technology is considered as an aid for the purpose 'manufacturing control'. For the realization of his task the employee needs informational technical aids which provide him with the necessary information and supporting functions for the planning and control of his task.

The design of shop floor information systems should be widely decentralized in order to increase the self-controlling ability of the decentralized manufacturing sections as well as to promote the interest of the employees in their work, their competence and their motivation.(Schwaninger, 1990).

This corresponds to the demand for the design of holistic tasks which include goal finding, planning and control functions. It follows that information systems have to offer these functions to make an integrated task design possible. In this context it is also necessary to clarify the type of information, communication and control structures used. For this reason the demands on the tools for manufacturing 
control systems from the perspective of the individuals and the decentralized organization must be examined.

\section{SOLUTION APPROACH}

Usually production management systems are based on implicit or explicit models that depict the characteristics of the controlled manufacturing system. A model is always a simplified copy of reality. Models for scheduling and control are open or closed control loops. Nowadays, EDP-systems for production planning and control as well as manufacturing control systems are based on these principles. For many new research projects the feedback control loop is still the basic concept. In order to describe the different scheduling levels of production planning and control as well as of manufacturing control, multistage feedback control loop systems have been developed.

This feedback control loop is also the basic principle of cybernetics. Cybernetics is the science of communication and control processes in living beings and machines. Its methods make it possible to look at structures in a wide sense and to depict different kind of systems from the perspective of their control structure (Probs., 1985).

Cybernetics is the science of communication and control in animal and machines.

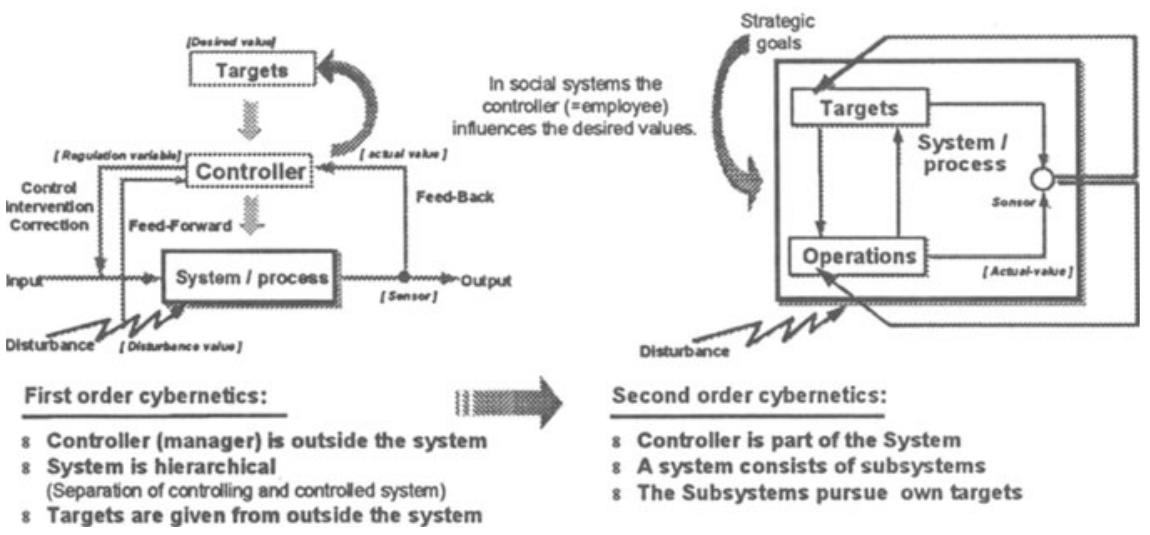

Idea:

The idea is to avoid situation depending instabilities by communication processes and not by changing the input values of the system.

Figure 4 First and Second Order Cybernetics [following (Schwaninger, 1994)]

Figure 4 shows the control of a process from the cybernetics perspective. Current output values of the process are fed back to the controller. The controller carries out a comparison between current and desired values. Based on this difference the controller generates correcting input data which are transmitted into the process. By the principle of feedforward it is possible to consider the effect of future 
disturbances on the process and to use this information for control decisions (Schwaninger, 1994).

This concept presented here is called 'First order cybernetics' (=cybernetics of mechanical systems).

\section{Definition of First Order cybernetics:}

'The cybernetics of systems that are observed from the outside as opposed to the cybernetics of systems involving their observers. First order cybernetics is concerned with circular causal processes, e.g. control, negative feedback, computing, adaption.' (Kippendorff, 1997)

The decisive interest in developing this approach was only of a technical nature (Espejo, 1993). Characteristic of the First Order Cybernetics is that the controller (e.g. the manufacturing controller) stands outside the controlled system and the targets are given from outside the system (Schwaninger, 1994). The application of cybernetic models on social systems demands a special view because first order cybernetics is not appropriate to meet the characteristics of individuals constituting an organization. In hierarchical social systems the controller actively influences the desired values of the system from outside. This is represented by the curved arrow in the left hand side of figure 4 . The outside controller is responsible to reach the given targets.

In contrast to technical systems in social systems similar to autonomous biological systems the principle of self-control gains in importance over the one of external control. Advanced manufacturing should be designed similar to such biological systems of high autonomy.

One example for an autonomous biological system is the balancing of the body temperature: Independent from outside disturbances - e.g. environmental temperature - the body temperatures are kept stable. In the same way manufacturing cells or islands should be able to keep their goals independently from external disturbances. Principles like autonomy, self-control, selforganization and self-reference acquire decisive organizational importance (Schwaninger, 1994). Hence, First and Second Order Cybernetics must be differentiated.

\section{Definition of Second Order Cybernetics:}

'The cybernetics of systems involving their observers as opposed to the cybernetics of systems that are observed from the outside. Second-order cybernetics is a more recent development, which involves the observer as a constitutive part of a circular organization and is concerned with Self-reference, Epistemology, Autonomy, SelfGovernment, Autopoiesis.' (Kippendorff, 1997)

In First Order Cybernetics the controller itself (i.e. the employee) is part of the system. The system is working goal oriented and consists of subsystems that pursue their own goals. The difference between the two points of views could be characterized as follows: 
First Order Cybernetics ('The cybernetics of observed systems')

- The controller (manager) is outside the system.

- The system is purpose orientated, i.e. the goals are given from outside into the system.

\section{Second Order Cybernetics ('The Cybernetics of observing systems')}

- The controller (manager) himself is part of the system.

- The system is goal oriented and it consists of subsystems, that pursue their own goals.

By the introduction of Second Order Cybernetics the concept of the feedback control loop is not replaced, but instead completed and acquires partly new meanings (Schwaninger, 1994).

The cybernetics of mechanical systems is based on the assumption of a clearly defined 'Black-Box' that can be used to handle the goals as well as the control and communication mechanism of the system.

The planning and control of a conventionally organized manufacture is based on a similar assumption. It was assumed that detailed planning targets of the controller or the PPC-System could be used to control the manufacturing process. It has transpired that rules for centralized detailed planning are not appropriate for the planning and control of modern decentralized manufacturing. Only unsatisfactory results could be obtained.

This conclusion corresponds to the knowledge we have of cybernetics. Scientific publications in the field of Second Order Cybernetics have demonstrated that the assumption of a clearly defined 'Black-Box' is not justified in the context of human activities and actions (Espejo, 1993).

From the perspective of the Second Order Cybernetics the handling that is to say, the management of situations is not primarily the result of decisions that are based on abstract models of the situation, but on communication processes that make a common interaction of all involved persons in the process possible. 


\section{Centralised manufacturing control:}

- Expediter is located in the centralised manufacturing control.

8 Manufacturing receives detailed instructions from the manufacturing control.

i External organisation.
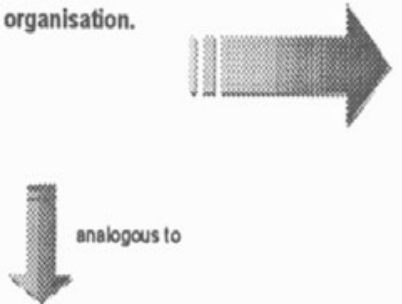

\section{First order cybernetics}

\section{Decentralised manufacturing control:}

s Manufacturing control gives rough targets with basic time limits.

Expediter works in decentralised units.

Expediter decides partly autonomously.

Employee decides how to control.

Self-organisation.

Co-ordination and co-operation by communication.

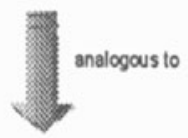

$\underline{\text { Second order cybernetics }}$

Idea:

Adjusting to situation depending instabilities by means of communication and co-operation.

Aid:

Autonomy, Self-organisation, Self-control

Figure 5 Manufacturing control and Cybernetics

The principle idea is to avoid having situation depending instabilities by means of communication processes and not by changing the input values of the 'Black-Box'. To co-operate as a community and to solve problems the knowledge of the persons that are involved in the process has to be included in the communication processes.

The distributed manufacturing control is based on this principle. The control does not happen by a detailed plan which is centrally scheduled but by manufacturing order pools with basic time limits which constitute targets for the decentralized organizational units. The realization of work is planned and controlled by the workers themselves in the decentralized units. As a result, experience and knowledge of the employee and the informal processes in the working system bear an important influence on the design and management of the control system. Therefore, it is necessary to consider the communication mechanism in these structures as well as the experience and knowledge of the workers. These forms of organizations work according to the principle of autonomy, self-organization and self-control. For this purpose the Second Order Cybernetics tries to offer appropriate mechanisms. A comparison of the characteristics of centralized and decentralized manufacturing control shows parallels between the situation of the manufacturing control in distributed organizational units and the characteristics of Second Order Cybernetics.

The importance of cybernetics for the design of problem solving and of decision making activities in sociotechnical systems has long since been recognized. Cybernetics makes it possible to model sociotechnical systems from the perspective of communication and control by analyzing and systematically designing communication processes and information flows. Therefore, cybernetics constitutes an ideal instrument for interdisciplinary co-operation (Gomez, 1981). 
Consequently, it is possible to consider the different designing aspects of manufacturing control and to develop an integrated approach in order to design the control tasks in a manufacturing system using an appropriate cybernetic method.

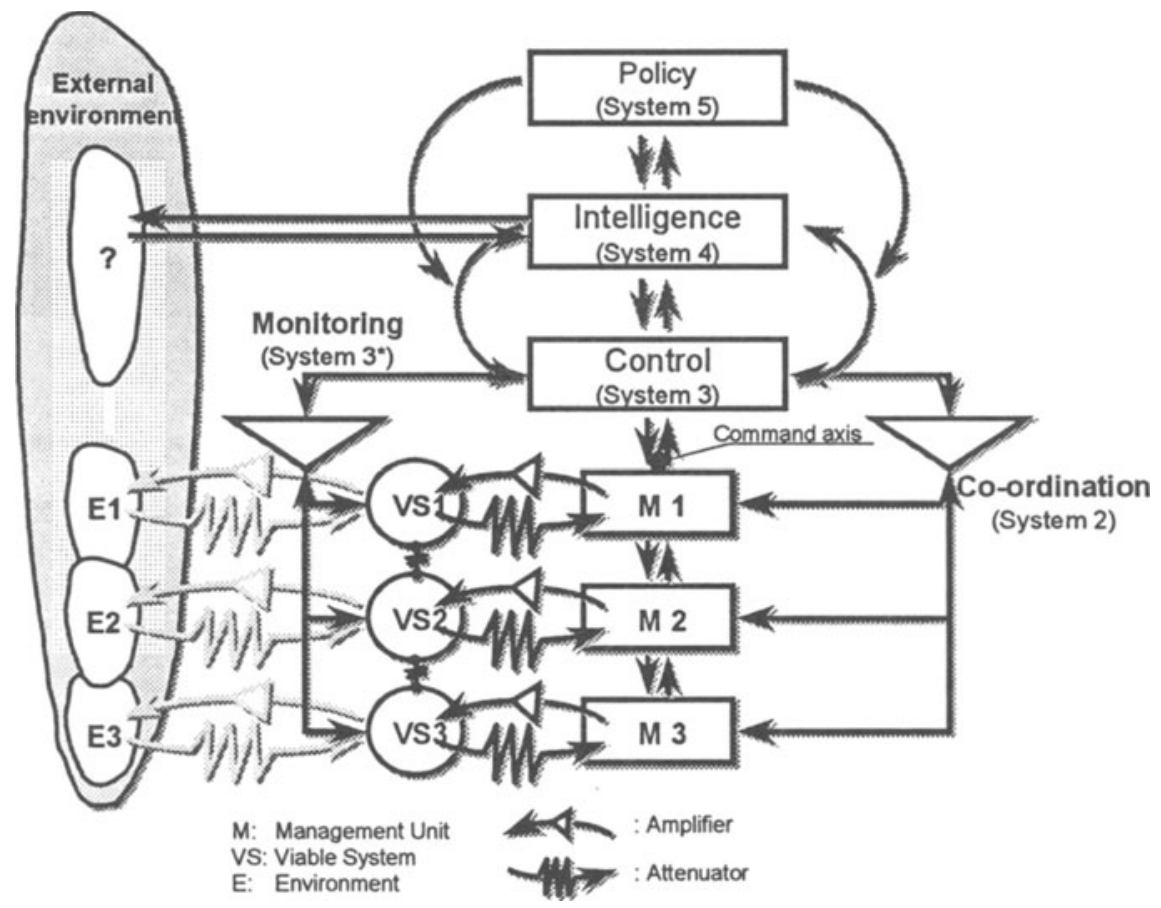

Figure 6 The structure of the Viable System Model [according to (Espejo, 1993)]

The 'Viable System Model (VSM)' is such a method (Figure 6). It was developed by the economist Stafford Beer to model and analyze sociotechnical systems and in particular, to model the control mechanism of such systems. The starting point was the question: Which communication structures and control mechanisms are necessary for an organization so that it may adapt to changing conditions as well as make use of experiences - i.e. to learn, to keep its identity and to develop - in other words to be viable (Malik, 1996).

To formalize the structural minimum requirements Beer used the human nerve system as an analogy. Based on the human nerve system he developed a structurally similar (homomorphist) model, which views at sociotechnical systems from the perspective of control. From Beer's point of view every viable system like the human nerve system is characterized by five subsystems of control, which express the necessary and minimal conditions to survive.(Probst, 1985). The model is based on the principles of viability, recursion and autonomy. Table 2 describes the control mechanisms that are included in the model. 
Table 2 Systems and their functions

\begin{tabular}{|c|c|}
\hline System & Function \\
\hline One & $\begin{array}{l}\text { (partly) autonomous organizational units are controlled within their } \\
\text { environment. Every system One has to be a viable unit. It means } \\
\text { that by the principle of recursion each system One again consists of } \\
\text { five subsystems (system One to Five). }\end{array}$ \\
\hline Two & $\begin{array}{l}\text { Co-ordination to achieve a higher goal using a network of } \\
\text { communication connections between the individual control } \\
\text { mechanisms of the partly autonomous units. }\end{array}$ \\
\hline Three & $\begin{array}{l}\text { A "higher" control mechanism serves the co-ordination and } \\
\text { optimization of any current activity in the system as a whole. This } \\
\text { control mechanism is responsible for the internal balance. }\end{array}$ \\
\hline Four & $\begin{array}{l}\text { A control mechanism that integrates the information from the } \\
\text { system's environment with the aim of establishing an external } \\
\text { balance. }\end{array}$ \\
\hline Five & $\begin{array}{l}\text { A superposed control mechanism co-ordinates the control activities } \\
\text { for the internal stabilization of the whole system (System Three) } \\
\text { plus the control activities which achieve a balance with the system's } \\
\text { environment depending on the targets and the purpose of the whole } \\
\text { system. }\end{array}$ \\
\hline
\end{tabular}

The Viable System Model provides a means of analyzing distributed organizations. It is a method to depict communication mechanisms that make the co-operation of the workers in a system possible. The model can be used for the design of 'viable' organizational structures (Espejo, 1993). The specific stress on the information connections between the systems and the recursion levels make the model an organization-theoretical basis for the architecture of information systems (Schuhmann, 1991).

Manufacturing control is done by certain activities of the workers (Figure 7). On the level of the machine operator a control activity is for example to sort the manufacturing orders according to certain targets. On the level of the expediter a control activity is for example the allocation of manufacturing orders to the different manufacturing areas. These activities are supported by certain (supporting) functions of the manufacturing control.

The necessary information and communication structures as well as supporting functions which realize these activities are structured by the Viable System Model. The result is a metamodel of the manufacturing control that fulfills the minimum 
requirement of an information system from the perspective of information, communication and control.

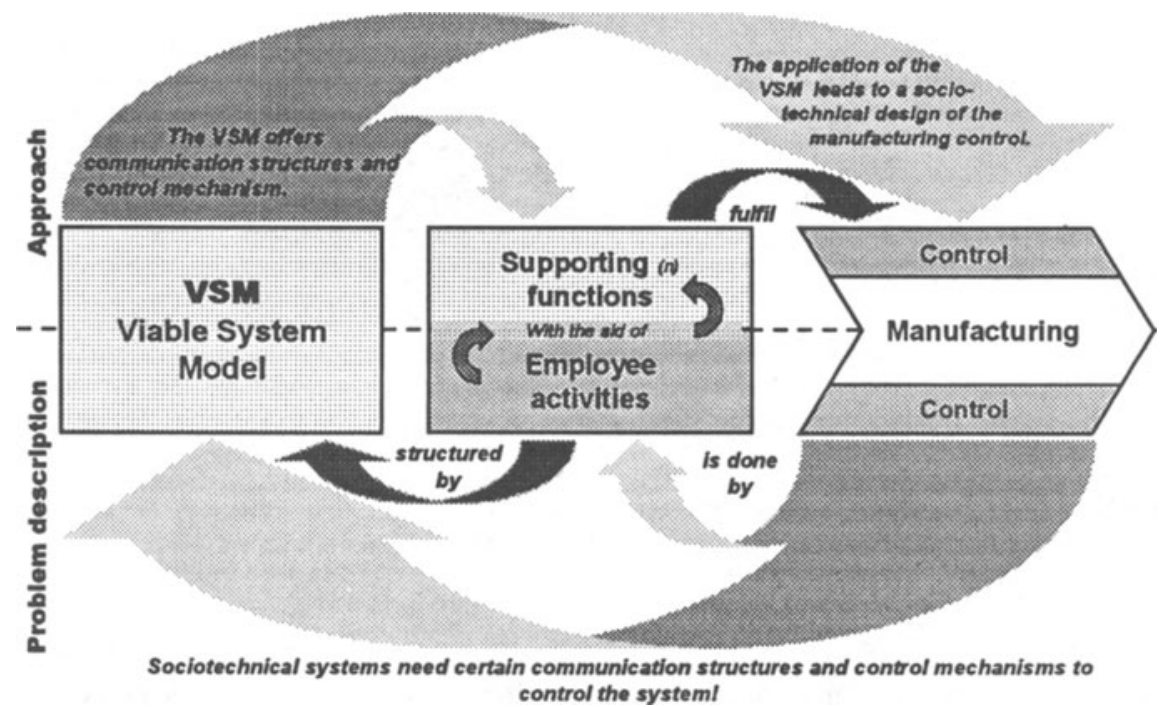

Figure 7 Solution approach with the VSM

The structure of the model makes it possible to model the manufacturing control from a sociotechnical perspective and to design the secondary task "manufacturing control" for the worker from a perspective of an integrated task design. That means that every worker should contribute to the target finding, planning, and control process. To support the worker by means of an information system from the perspective of cybernetics it is necessary that the target finding, planning and control processes correspond with the organizational structure (Schwaninger, 1994). The minimal organizational structure necessary for the manufacturing control which is required for that purpose is shown in Figure8.

To guarantee a wide autonomy the 'Decentralized Scheduling Mechanism' receives a stock of orders with basic time limits over the command axis. Inside the 'Decentralized Scheduling Mechanism' the detailed planning for the order processing in the decentralized manufacturing unit is carried out. By means of a calculated distribution of the stock of orders to the individual partly autonomous units the cohesion of these units in the sense of a given target is striven for. This vertical co-ordination function is the task of the control mechanism 'Control'.

The function of the co-ordination mechanism 'Order Co-ordination' is to avoid and regulate disturbances between the individual decentralized units. This mechanism pursues the goal of achieving synergy effects which are striven for by the plan of the mechanism 'Control'. So the control demands on the system 'Control' are reduced. The more powerful the horizontal co-ordination function is, the more autonomy can be guaranteed for the distributed manufacturing units. 
In order to realize its co-ordination function the 'Order Co-ordination' receives information about the stock of orders of the individually scheduled decentralized units from the system 'Control'. The 'Decentralized Scheduling Mechanisms' inform the 'Order Co-ordination' about their current status of the detailed planning, their current progress of orders as well as about possible derivations from time targets and eventually resulting new order sequences.

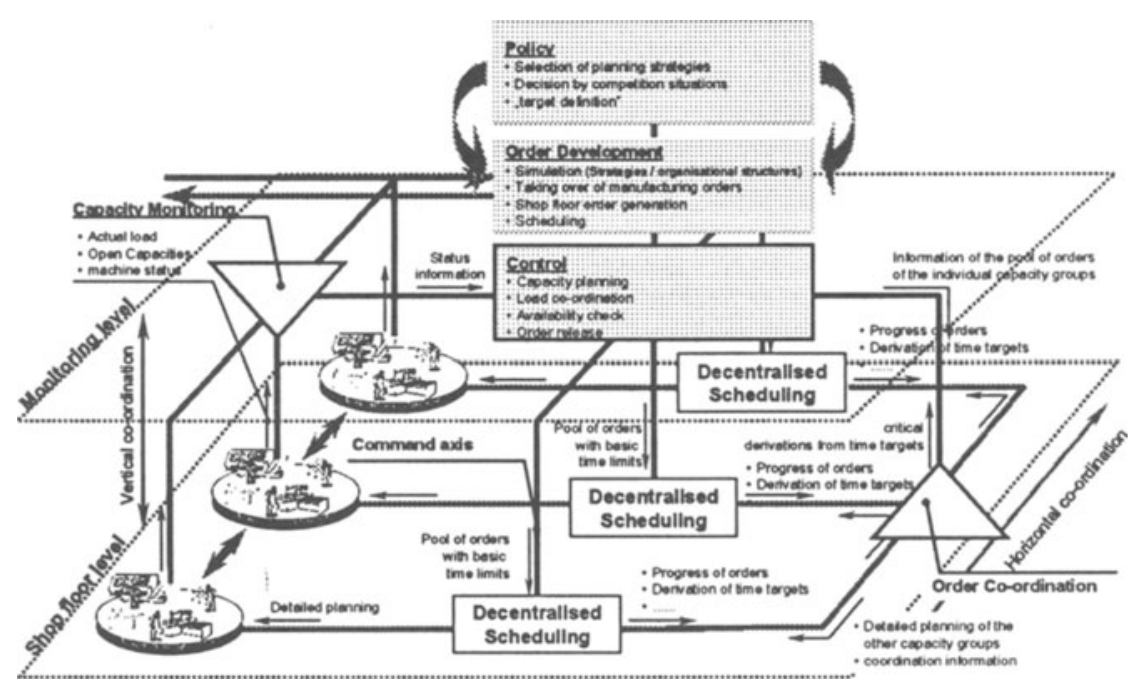

Figure 8 Organizational structure of the shop-floor management

The 'Order Co-ordination' informs every 'Decentralized Scheduling Mechanism' about the current detailed planning situation of the other units. It also derives co-ordination information to regulate possible disturbances, as a result of the comparison between the targets of the 'Control' and the current progress of orders that is to say derivations from time targets of the decentralized units.

The 'Order Co-ordination' only passes information about derivations from time targets that will lead to inadjustable disturbances to the 'Control'. However, to fulfill the control function it is necessary for the system 'Control' to obtain unfiltered information of the real status of the decentralized units (Espejo, 1989). For this to happen, a monitoring function is necessary. In the model this monitoring-mechanism is represented by the 'Capacity Monitoring'. It belongs to the system 'Control'.

The 'Capacity Monitoring' delivers information to the 'Control' about the real status of the decentralized manufacturing units, global targets such as capacity utilization or a certain throughput time. For this reason it monitors the current loading with manufacturing orders, possible open capacities as well as possible disturbances of machines or workers and passes is information to the system 'Control'. With this information it is possible for the 'Control' to cross-check the information of the 'Order Co-ordination' and the direct information of the 'Decentralized Scheduling Mechanism'. The described communication channels 
of the control mechanism 'Control' (including 'Capacity Monitoring'), the 'Decentralized Scheduling Mechanism' and 'Order Co-ordination' set up the monitoring and control mechanism of the manufacturing control and correspond to the systems 'Three', 'Two' and 'One' of the Viable System Model.

To adapt the manufacturing and the control mechanism to new situations, which result from, changed market conditions, it is necessary to provide appropriate mechanisms for the shop floor management in the organization structure. This is the task of the meta system that consists of the control mechanisms 'Control', 'Order Development' and 'Policy'. These mechanisms correspond to the systems 'Three', 'Four' and 'Five' of the Viable System Model.

The task of the control mechanism 'Policy' is to determine the basic goals and strategic rules for the whole job shop management. It derives the basic behavior of the job shop management from targets of system five of the higher recursion level and from the information of the external (=market) respectively internal (=manufacturing) environment. In the sense of the manufacturing control this could be for example planning strategies or setting of long-term targets for capacity balancing. In the long term the establishment of specific forms of manufacturing organizations are feasible as a target of the control mechanism 'Policy'. Another task of system Five is the co-ordination of the internal environment and the external environment. This is necessary to remain viable in the future and to be able to compete with new market conditions.

The control mechanism 'Order Development' has the function to process the orders and to develop possibilities to push the manufacturing orders through the production on time. That includes the optimization of planning strategies and the manufacturing organization itself. In the short term different order sequences can be simulated to evaluate the different effects on the manufacturing process.

Supporting functions from the perspective of the manufacturing control are for example. the time scheduling as well the taking over or splitting of manufacturing orders. In the medium-term the suitability of different planning methods can be examined. In the long-term the task is to optimize the manufacturing organization for instance by simulating of different organizational structures and orders of operations.

The solution proposals developed by the 'Order Development' are transmitted to the operative 'Control' that examines the proposals from the perspective of the internal situation in the manufacturing area. In the same way the 'Order Development' examines proposals of the 'Control' from its perspective. It is a continuous co-ordination process between these two systems.

From the perspective of the manufacturing control the capacity planning, the load co-ordination, the availability check as well as the order release are all functions that support the task of the system 'Control'. In general the co-ordination process takes place in the short and medium term. The co-ordination of these two control mechanisms is monitored by the control mechanism 'Policy' according to global company targets. If there is a conflict this mechanism is the highest authority.

The previous description demonstrates the transfer of the control mechanism of the manufacturing control to the Viable System Model of Stafford Beer. In the 
following chapter the realization of an information system that is based on this approach is presented.

\section{MOBILEIT-S}

The model based toolbox for integrated manufacturing control systems with simulation kernel is a concept for an information system that offers the possibility to configure system functions by designing a factory model.

For this reason the organizational structure of the job shop management that was mentioned with the VSM in the previous chapter, is described in form of general structures in a metamodel. This model offers the structural framework for general reference models of the manufacturing order processing for different manufacturing organizations like single item and serial production.

The model elements that are described in the reference model correspond to the ones in reality. In this way a machine in the model correspond to a machine in reality and the depicted control processes correspond to the ones that are necessary to control the shop floor. The elements are oriented to existing notations of a companies hierarchy, operation resources, manufacturing aids, order structures and working-papers.

From the perspective of the manufacturing control the behavior of the real manufacturing elements is reproduced by the methods and attributes of each corresponding model object. Factory objects with the same or similar structure and behavior are objects of the same class.

The building of a specific factory model is done by deriving the model elements from the reference model. The object-oriented concept offers a way to refine the model step by step by specifying the necessary changes in each case.

Since it is easy to alter the factory model and the included control processes during the run-time it is possible to adjust the model according to changing demands.

Various control strategies and factory behavior are implemented by the use of event-driven simulation and interaction of the factory objects. Therefore, it is possible to analyze planned manufacturing structures new control strategies and different order sequences for the job shop scheduling. In the same way it is possible to identify dependencies and conformities to laws of the processes and to use the results for planning and control in the meaning of continuous optimization.

The prototype of the system represents an integrated solution that offers functions of current monitoring system as well as certain functions of factory planning systems.

By combining a generally used factory model with a powerful model based simulation as well as with the application of an object-oriented software architecture a flexible information system is formed that allows the user a continuous adaptation to changing production conditions. As a result a continuous improvement process is provided. The use of simulation offers an aid that supports the preparation and evaluation of decisions in the manufacturing area. This ranges from the short-term manufacturing control to long-term investment decisions. 
The development of this system is sponsored by the development-program 'Production 2000 - Strategies for the production in the 21. Century'. It is promoted by the German federal ministry of education, science, research and technology (BMBF). Four companies, two software houses and two departments of different universities are involved in this project.

\section{REFERENCES}

DLR/Projektträgerschaft: Arbeit und Technik, Leitstände für die Werkstatt; Bremerhaven: Wirtschaftsverlag, 1994.

Espejo, R.: The VSM revisited. In: The Viable System Model - Interpretations and Applications of Stafford Beer's VSM.Espejo, R.; Harden, R. (Hrsg.).Chichester, New York: John Wiley \& Sons Ltd., 1989.

Espejo, R.; Schwaninger, M.: Organizational fitness: corporate effectiveness through management cybernetics. Frankfurt a.M.; New York: Campus Verlag 1993.

Gomez, P.: Modelle und Methoden des systemorientierten Management. Bern; Stuttgart: Verlag Paul Haupt, 1981.

Grabowski, H.; Grein, G.; Milde, P.; Weber, U.: Unternehmensmodelle zur Konzeption von Informationssystemen. ZWF 90 (1995) 7-8, S. $354-356$.

Herrmann, W.; Hug, B.: Werkstattnahes Produktionsmanagement und PPS. CIMManagement 11 (1995) 3, S. 47-51.

Hirsch-Kreinsen, H.: Restrukturierung von Unternehmen - Ziele, Formen und Probleme dezentraler Organisation in: Produzieren im 21. Jahrhundert Herausforderungen für die deutsche Industrie. Lutz, B.; Hartmann, M.; HirschKreinsen, H. (Hrsg.), Campus-Verlag, Frankfurt am Main, New-York 1996.

Kippendorff, K.: Klaus Krippendorff's Dictionary of Cybernetics. Principa Cybernetica Web: URL:http://pespmcl.vub.ac.be/ASC/First-_cyber.html; Email: fkk@asc.upenn.edu; [Online: June 1997]

Linsen, M.: Fit für die Zukunft - Wohin geht der Trend bei PPS? AV 32 (1995) 2, S. $112-114$.

Malik, F.: Strategie des Managements komplexer Systeme - Ein Beitrag zur Management-Kybernetik evolutionärer Systeme. Paul Haupt Verlag, Bern, Stuttgart, Wien; 1996.

Maßberg, W.; Thiem, I.: Objektorientiertes Referenzmodell der Auftragsbearbeitung. ZWF 92 (1997) 1-2, S. $38-41$.

Poensgen, W.: Vom Taylorismus zum Prozeßmanagement - Individuelles Gestalten von Organisationen, Prozessen, Funktionen und Daten. AV 31 (1994) 6, S. $372-373$.

Poensgen, W.: Informationstechnik für das Re-Engineering. ZWF 90 (1995) 3, S. $98-99$.

Probst, G. J. B.: Die Entwicklung zu modernen systemorientierten Organisationsmodellen; in: Unternehmensorganisation - Entwicklungen in Theorie und Praxis. Ulrich, H.; Probst, G. (Hrsg.). Bern; Stuttgart: Verlag Paul Haupt, 1985. 
Rohloff, M.: Produktionsmanagement in modularen Organisationsstrukturen: Reorganisation der Produktion und objektorientierte Informationssysteme für verteilte Planungsinstrumente. München, Wien: Oldenbourg, 1995.

Schumann, W.: Informationsmanagement - Unternehmensfïhrung und Informationssysteme aus systemtheoretischer Sicht. Frankfurt a. M.: Campus Verlag, 1991.

Schwaninger, M.: Managementsysteme. Frankfurt a. M.: Campus Verlag, 1994.

Ulich, E.:Arbeitspsychologie.3., überarbeitete und erweiterte Auflage. Stuttgart: Schäffer Poeschel, 1994.

Verein Deutscher Werkzeugmaschinenfabriken: Autonome, Kooperative Produktionssysteme. Frankfurt 1995.

Wiegershaus, U.; Hagen, A.; Lackner, U.: Marktführerschaft durch kundenorientierte Servicestrukturen. VDI-Z 138 (1996), Nr. 6 - June, S. 94 97.

Wildemann, H.: Netzwerkstrukturen als neue Form der Unternehmensorganisation. ZWF 91 (1996) 1-2, S.12-16.

\section{BIOGRAPHY}

Prof. Dr.-Ing. Maßberg:

Born 11. May 1932 at Karlsruhe, Germany. Electrical Engineering studies at the University RWTH Aachen; 1965 Doctor of Mechanical Engineering by Prof. Dr.Ing. H. Opitz at the RWTH Aachen; From 1965 to 1975 leading positions in several companies; Since 1976 holder of the chair 'Production Systems' and member of the Board of Automation Research Institute Ruhr-University Bochum. From 1990 till 1993 Rector of the Ruhr-University Bochum; From 1993 till 1997 Chairman of the German Academic Society for Production Engineering (WGP).

Michael Bäcker:

Born 21. July 1970 at Siegen, Germany. Mechanical Engineering studies at the Ruhr-University Bochum; Since April 1997 research assistant at the Automation Research Institute (Ruhr-University Bochum).

Harald Schallner:

Born 22. September 1969 at Münster, Germany. Computer Science studies at the University Paderborn; Since October 1996 research assistant at the Automation Research Institute (Ruhr-University Bochum).

Ingo Thiem:

Born 4. December 1964 at Wattenscheid, Germany. Study of Mechanical Engineering at the Ruhr-University Bochum and University Dortmund; From 1990 till 1993 engineer for logistics at FLACHGLAS AG; Since 1993 research assistant at the Automation Research Institute (Ruhr-University Bochum). 